\title{
Two energy balance closure approaches: applications and comparisons over an oasis-desert ecotone
}

\author{
PAN Xin ${ }^{1,2}$, LIU Yuanbo ${ }^{1 *}$, FAN Xingwang ${ }^{1}$, GAN Guojing ${ }^{1}$ \\ ${ }^{1}$ Key Laboratory of Watershed Geographic Sciences, Nanjing Institute of Geography and Limnology, Chinese Academy of \\ Sciences, Nanjing 210008, China; \\ ${ }^{2}$ University of Chinese Academy of Sciences, Beijing 100049, China
}

\begin{abstract}
Studies of energy balance that rely on eddy covariance (EC) are always challenged by energy balance closure, which is mainly caused by the underestimations of latent heat flux (LE) and sensible heat flux (Hs). The Bowen ratio (BR) and energy balance residual (ER) approaches are two widely-used methods to correct the LE. A comprehensive comparison of those two approaches in different land-use types is essential to accurately correcting the LE and thus improving the EC experiments. In this study, two energy balance approaches (i.e., BR and ER) were compared to correct the LE measured at six EC sites (i.e., three vegetated, one mixed and two non-vegetated sites) in an oasis-desert ecotone of the Heihe River Basin, China. The influences of meteorological factors on those two approaches were also quantitatively assessed. Our results demonstrated that the average energy closure ratio ((LE+Hs)/(Rn-Gs); where $\mathrm{Rn}$ is the surface net radiation and Gs is the surface soil heat flux) was approximately close to 1.0 at wetland, maize and village sites, but far from 1.0 at orchard, Gobi and desert sites, indicating a significant energy imbalance at those three latter sites. After the corrections of BR and ER approaches that took into account of soil heat storage, the corrected LE was considerably larger than the EC-measured LE at five of six EC sites with an exception at Gobi site. The BR and ER approaches yielded approximately similar corrected LE at vegetated and mixed sites, but they generated dissimilar results at non-vegetated sites, especially at non-vegetated sites with low relative humidity, strong wind, and large surface-air temperature difference. Our findings provide insight into the applicability of BR and ER approaches to correcting EC-based LE measurements in different land-use types. We recommend that the BR-corrected and ER-corrected LE could be seriously reconsidered as validation references in dry and windy areas.
\end{abstract}

Keywords: energy balance closure; eddy covariance; Bowen ratio-energy balance approach; energy balance residual approach; Heihe River Basin

Citation: PAN Xin, LIU Yuanbo, FAN Xingwang, GAN Guojing. 2017. Two energy balance closure approaches: applications and comparisons over an oasis-desert ecotone. Journal of Arid Land, 9(1): 51-64. doi: 10.1007/s40333-016-0063-2

\section{Introduction}

The energy exchanges within the land-atmosphere interface play a critical role in forming the Earth's climate systems (Stoy et al., 2013) and the role is explicitly expressed by energy balance. The balance includes three basic components: energy intake, energy expenditure and energy storage (Bray et al., 2003) and the three components are often tightly coupled through either positive or negative feedback mechanisms (Blundell et al., 2003). The energy balance exerts influence not only on the Earth's climate systems, but also on the hydrological cycles and the

*Corresponding author: LIU Yuanbo (E-mail: ybliu@niglas.ac.cn)

Received 2016-01-27; revised 2016-06-15; accepted 2016-07-15

(C) Xinjiang Institute of Ecology and Geography, Chinese Academy of Sciences, Science Press and Springer-Verlag Berlin Heidelberg 2017 
biogeochemical cycles (e.g., Meyers et al., 2004; Wild, 2008; Mercado et al., 2009; Moiwo and Tao, 2015).

The energy stored in the canopy layer is often negligible (Meyers and Hollinger, 2004; Haverd et al., 2007). If the influences of ice melt, biomass storage and advection on the energy balance are also negligible, the energy balance within the land-atmosphere interface (i.e., near the land surface) can be generally expressed as: Rn-Gs=LE+Hs (Meyers and Hollinger, 2004; Haverd et al., 2007). Where $\mathrm{Rn}$ is the surface net radiation and Gs the surface soil heat flux (Leuning et al., 2012); LE is the latent heat flux and Hs the sensible heat flux, both being measured using eddy covariance method (EC) (Twine et al., 2000; Baldocchi et al., 2001; Heusinkveld et al., 2004; Wang and Dickinson, 2012). Rn can be directly measured with satisfactory accuracy (Foken, 2008). Gs comprises the heat flux and the soil heat storage. It should be mentioned that neglecting the soil heat storage may result in inaccurate Gs estimations (Heusinkveld et al., 2004) and that the inaccuracy problem can be alleviated if the damping effects of soil temperature and moisture profiles are corrected (Yang and Wang, 2008; Leuning et al., 2012). It should be stressed that the heat fluxes (LE and Hs) measured using EC are usually underestimated (Wilson et al., 2002), and the sum of estimated latent and sensible heat fluxes ( $\mathrm{LE}+\mathrm{Hs})$ is thus smaller than the available energy flux (Rn-Gs) (Wang et al., 2009; Franssen et al., 2010), resulting in energy balance closure (i.e., energy imbalance) (Kristensen et al., 1997; Mauder et al., 2006, 2007; Liu et al., 2009; Xu et al., 2013).

It should be reiterated that the energy balance closure (i.e., energy imbalance) is directly related to the EC-resulted underestimations of the latent and sensible heat fluxes (Aubinet et al., 1999; Wilson et al., 2002) and that it has been one of the major challenges in the studies of the energy exchange processes within the land-atmosphere interface (Oliphant et al., 2004; Oncley et al., 2007; Wang et al., 2009). The aforementioned energy balance closure problem has twofold implications: (1) how energy flux measurements should be interpreted, and (2) how these estimates should be corrected or calibrated with model simulations or/and field experiments (Twine et al., 2000). A number of methods have been proposed to correct the EC-measured energy fluxes (Castellví, 2008; Kidston et al., 2010; Liu et al., 2012), and the most frequently adopted methods are the Bowen ratio (BR) approach (Twine et al., 2000; Barr et al., 2012) and the energy balance residual (ER) approach (Schotanus et al., 1983; Amiro, 2009). The widely-used BR approach is quite simple: proportionally assigning the underestimated energy to LE and Hs (Twine et al., 2000; Wohlfahrt et al., 2009). The ER approach regards the LE as the energy balance residual (Rn-Gs-Hs) (Amiro, 2009) and this approach was mainly applied to vegetated regions. It should be particularly noted that the LE is highly dependent on the underlying surfaces and that it is thus essential to assessing the applicability of BR and ER approaches to different land-use types for advancing the EC-based studies of energy balance.

This study took advantage of the Heihe Watershed Allied Telemetry Experimental Research (HiWATER) project that established well-calibrated EC sites in an oasis-desert ecotone within the Heihe River Basin (Xu et al., 2013; Wang et al., 2015). Specifically, the EC-based LE values in different land-use types measured during the period from 25 June to 15 September (2012) were corrected using BR and ER approaches. The purpose was to assess the applicability of these two approaches to different land-use types for advancing the EC-based studies of energy balance. Again, neglecting the soil heat storage may result in inaccurate Gs estimations. In this study, the damping effects of soil temperature and moisture profiles were corrected to alleviate the inaccuracy problem. Furthermore, as the LE values, corrected either using BR approach or using ER approach, may be affected by meteorological factors, the influences of meteorological factors were also assessed.

\section{Materials and methods}

\subsection{Study area}

The study sites are situated in an oasis-desert ecotone of Zhangye City $\left(38^{\circ} 51^{\prime} \mathrm{N}, 100^{\circ} 25^{\prime} \mathrm{E} ; 1519 \mathrm{~m}\right.$ 
a.s.1.) within the Heihe River Basin, Northwest China. The Heihe River Basin is the second largest inland river basin in China and covers an area of approximately $130 \times 10^{3} \mathrm{~km}^{2}$. The study area, an oasis-desert ecotone of Zhangye City, is characterized by a continental climate with a long dry season (from October to May of next year) and a short rainy season (from June to September). The minimum, maximum and annual mean temperatures are $-31.0^{\circ} \mathrm{C}, 39.1^{\circ} \mathrm{C}$ and $7.4^{\circ} \mathrm{C}$, respectively. Average annual precipitation is $115.6 \mathrm{~mm}$ and average annual evaporation is as high as $2107.1 \mathrm{~mm}$.

\subsection{Experiment design and data collection}

The data used in this study were collected from six EC sites of the HiWATER project (Fig. 1) (Li et al., 2013). And, all those data from the measuring period of 25 June to 15 September (2012) were downloaded from the Cold and Arid Regions Science Data Center (http://westdc.westgis.ac.cn) (Liu et al., 2011; Xu et al., 2013). It should be stressed that the downloaded LE and Hs data were converted from the in situ observed data. The conversion involved the following data and steps: spike detection, $\mathrm{H}_{2} \mathrm{O}$ lag relative to the vertical wind component, sonic virtual temperature (Schotanus et al., 1983), coordinating rotation (Wilczak et al., 2001), density fluctuation (Webb et al., 1980), and frequency response (Lee et al., 2004; Liu et al., 2012). The six EC sites were classified into three land-use categories: vegetated sites (maize land, orchard land and wetland), mixed site (village), and non-vegetated sites (desert and Gobi). The vegetated and mixed sites represent the oasis area, whereas the non-vegetated sites represent the desert area. The descriptive information of each site is listed in Table 1.

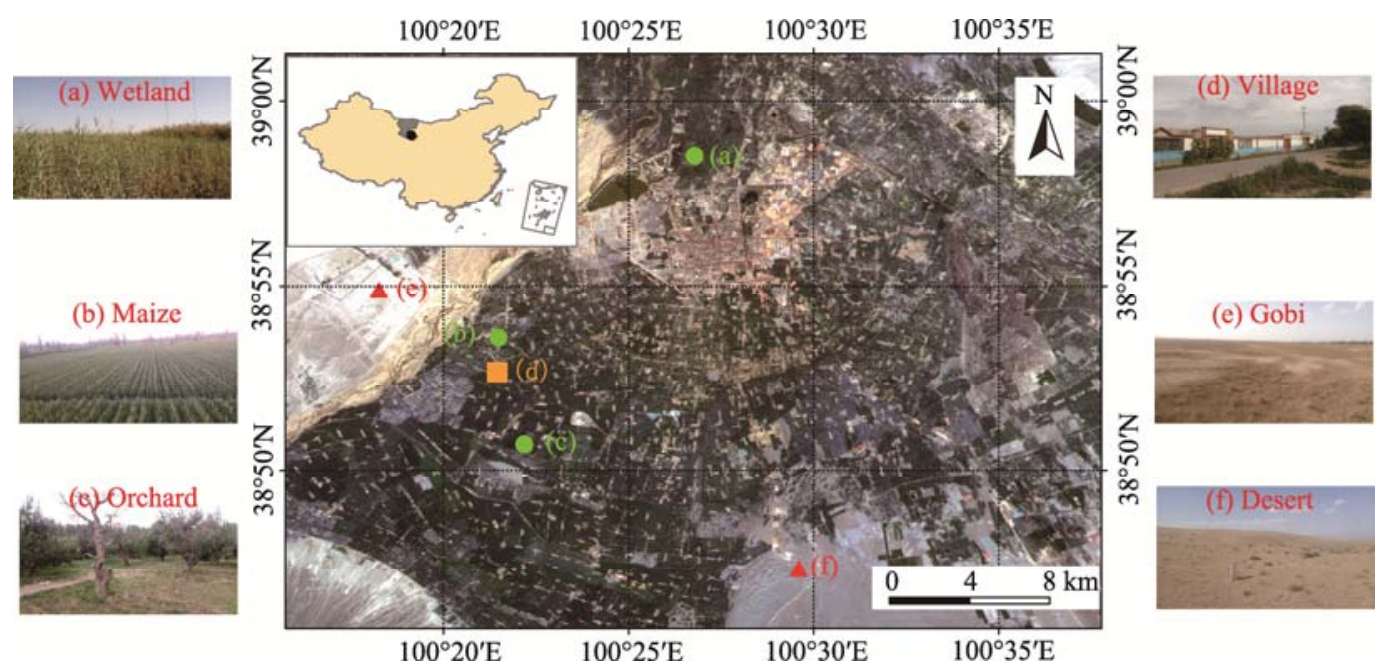

Fig. 1 Locations of EC (eddy covariance) sites and land-use types of the EC sites

Table 1 Descriptive information of EC (eddy covariance) sites

\begin{tabular}{|c|c|c|c|c|c|}
\hline Site & & Longitude & Latitude & Altitude (m) & EC height (m) \\
\hline \multirow{3}{*}{ Vegetated } & Wetland & $100^{\circ} 26^{\prime} 45^{\prime \prime} \mathrm{E}$ & $38^{\circ} 58^{\prime} 30^{\prime \prime} \mathrm{N}$ & 1460 & 5.2 \\
\hline & Maize & $100^{\circ} 22^{\prime} 19^{\prime \prime} \mathrm{E}$ & $38^{\circ} 51^{\prime} 21^{\prime \prime} \mathrm{N}$ & 1556 & 34.0 \\
\hline & Orchard & $100^{\circ} 22^{\prime} 12^{\prime \prime} \mathrm{E}$ & $38^{\circ} 50^{\prime} 41^{\prime \prime} \mathrm{N}$ & 1559 & 7.0 \\
\hline Mixed & Village & $100^{\circ} 21^{\prime} 28^{\prime \prime} \mathrm{E}$ & $38^{\circ} 52^{\prime} 40^{\prime \prime} \mathrm{N}$ & 1561 & 4.2 \\
\hline \multirow{2}{*}{ Non-vegetated } & Gobi & $100^{\circ} 18^{\prime} 14^{\prime \prime} \mathrm{E}$ & $38^{\circ} 54^{\prime} 54^{\prime \prime} \mathrm{N}$ & 1562 & 4.6 \\
\hline & Desert & $100^{\circ} 29^{\prime} 34^{\prime \prime} \mathrm{E}$ & $38^{\circ} 47^{\prime} 20^{\prime \prime} \mathrm{N}$ & 1594 & 4.6 \\
\hline
\end{tabular}

The LE data and the Hs data measured using EC (hereinafter called LE and Hs, respectively) at an interval of $30 \mathrm{~min}$ were used in this study. It deserves mentioning that the following two relevant researches provided quite useful references to this study: (1) the EC metrics were inter-compared and validated over the Gobi for the period of 14-24 May (2012) by Xu et al. (2013) and (2) data consistency was insured by the instrument inter-calibration processes 
(including uniform data processing steps and standards) (Wang et al., 2015). To avoid the underestimations of LE and Hs (Liu et al., 2012), we only selected daytime (08:00-17:30, local solar time) data and corrected the original LE data using both the BR and ER approaches.

In the field, the Rn and Gs were measured by pyranometers/pyrgeometers and heat flux plates, respectively. In this study, the $\mathrm{Rn}$ and Gs data were collected at an interval of $10 \mathrm{~min}$ and then averaged into 30-min data to match the 30-min LE and Hs data. The auxiliary data were also field collected and they include soil data (i.e., moisture and temperature) measured by soil moisture and temperature probes and air data (i.e., relative humidity, wind speed and air temperature) measured by automatic meteorological stations. In addition, the upward long-wave radiation was also measured.

\subsection{Methods}

\subsubsection{Soil heat storage correction for Gs}

Gs comprises the heat flux at certain soil depths (at $6 \mathrm{~cm}$ in HiWATER) and the soil heat storage above certain soil depths (i.e., above $6 \mathrm{~m}$ ). Again, it should be stressed that neglecting the soil heat storage may result in inaccurate Gs estimations (Heusinkveld et al., 2004) and that the damping effects of soil temperature and moisture profiles can be corrected to alleviate the inaccuracy problem (Yang and Wang, 2008; Leuning et al., 2012). In this study, the accuracy of Gs estimations was improved by correcting the damping effects of soil temperature and moisture profiles (Yang and Wang, 2008):

$$
G s=G\left(z_{r e f}\right)+\frac{1}{\Delta t} \sum_{z_{r e f}}^{z}\left[\rho_{s} c_{s}\left(z_{i}, t+\Delta t\right) T\left(z_{i}, t+\Delta t\right)-\rho_{s} c_{s}\left(z_{i}, t\right) T\left(z_{i}, t\right)\right] \Delta z .
$$

Where, $z(\mathrm{~m})$ is the soil depth, $\Delta z(\mathrm{~m})$ the measuring interval of soil profiles, $z_{\text {ref }}(\mathrm{m})$ the depth of soil heat plate; $G\left(z_{r e f}\right)\left(\mathrm{W} / \mathrm{m}^{2}\right)$ is the heat flux measured by soil heat flux plate, $T(\mathrm{~K})$ the soil temperature, $t(\mathrm{~s})$ the sampling time, $\Delta t(\mathrm{~s})$ the sampling interval; and $\rho_{s} c_{s}(\mathrm{~J} /(\mathrm{kg} \cdot \mathrm{K}))$ is the soil heat capacity, which can be calculated based on soil water content $(\theta)$ and soil porosity $\left(\theta_{s a t}\right)$ (i.e., $\left.\rho_{s} \mathcal{c}_{s} \approx 2.1 \times 10^{6} \times\left(1-\theta_{\text {sat }}\right)+4.2 \times 10^{6} \times \theta\right)$.

\subsubsection{Bowen ratio (BR) correction approach}

The BR approach uses the independent Rn and Gs measurements to correct the EC-based LE measurements (Twine et al., 2000). The Bowen ratio $(\beta)$ is expressed as: $\beta=H s / L E$ (Bowen, 1926). Ideally, the available energy flux (Rn-Gs) is equal to the sum of measured latent and sensible heat fluxes (LE+Hs). Thus, if the available energy flux is known, then the LE can be expressed by the available energy flux and Bowen ratio $(\beta)$ as follows:

$$
B R L E=\frac{1}{1+\beta}(R n-G s)
$$

Where, BRLE $\left(\mathrm{W} / \mathrm{m}^{2}\right)$ is the Bowen ratio-corrected LE with soil heat storage correction; $R n$ $\left(\mathrm{W} / \mathrm{m}^{2}\right)$ is the net radiation; and $G s\left(\mathrm{~W} / \mathrm{m}^{2}\right)$ is the corrected soil heat flux with soil heat storage correction. In practice, weights are assigned to LE and Hs according to the Bowen ratios (Wilson et al., 2002).

\subsubsection{Energy balance residual (ER) correction approach}

Assuming that Rn, Gs and Hs can be accurately measured, then the relatively accurate LE can be derived from the energy balance expression $\mathrm{Rn}-\mathrm{Gs}=\mathrm{LE}+\mathrm{Hs}$ (Schotanus et al., 1983; Amiro, 2009). Accordingly, the corrected LE is as follows:

$$
E R L E=R n-G s-H s .
$$

Where, $E R L E\left(\mathrm{~W} / \mathrm{m}^{2}\right)$ is the energy balance-corrected LE with soil heat storage correction, whereas $H s\left(\mathrm{~W} / \mathrm{m}^{2}\right)$ is the sensible heat flux directly measured by EC and is often underestimated because of the shortcomings of the triaxial sonic anemometer (Kristensen et al., 1997; Lee et al., 2004).

\subsubsection{Influences of advection on energy balance closure}

The magnitude of energy balance closure is related to the advection to some degree (Foken, 2008). The advection $\left(X ; \mathrm{W} / \mathrm{m}^{2}\right)$ is defined as follows: $X=\Delta /(\Delta+\gamma) \times(R n-G s)-L E$ (McNaughton, 1983). 
Where, $\Delta$ is the slope of the saturated vapor pressure at certain air temperatures and $\gamma$ the psychometric constant. $X$ is negative for advective enhancement and positive for advective depression. Moreover, the percentage contribution $\left(R_{a d}\right)$ of advection $(X)$ to LE is defined as follows: $R_{a d}=-X / L E$ (Smith et al., 1997). Based on $X$ and $R_{a d}$, the influences of advection on energy balance closure at all EC sites can be evaluated.

2.3.5 Indices for accuracy assessment

Bias, standard deviation (SD) and root mean square error (RMSE) expressed in Equations 4-6 (Nagol et al., 2009) were used to evaluate the acceptancy of the two correction approaches:

$$
\begin{gathered}
\text { Bias }=\frac{\sum_{i=1}^{n} \text { data }_{i}-\text { ref }_{i}}{n} . \\
S D=\sqrt{\frac{\sum_{i=1}^{n}\left(\text { Bias }_{i}-\overline{\text { Bias }_{i}}\right)^{2}}{n} .} \\
R M S E=\sqrt{\frac{\sum_{i=1}^{n}\left(\text { Bias }_{i}-\overline{\text { Bias }_{i}}\right)^{2}}{n} .}
\end{gathered}
$$

Where, data $_{i}$ is the data to be evaluated, ref $_{i}$ the reference of evaluation; $\overline{\text { Bias }_{i}}$ is the average value of Bias and $n$ is the number of data pairs used in the comparisons.

In addition, the linear regression was used to analyze the agreements or discrepancies among the LE data sets. The correlation coefficient $\left(R^{2}\right)$, Slope and Intercept of the linear fit were subsequently obtained (Squires, 2001):

$$
\begin{gathered}
R^{2}=1-\frac{\sum_{i=1}^{n}\left(\text { data }_{i}-r e f_{i}\right)^{2}}{\sum_{i=1}^{n}\left(\text { data }_{i}-\overline{r e f}\right)^{2}} . \\
\text { Slope }=\frac{\sum_{i=1}^{n} \text { data }_{i}\left(r e f_{i}-\overline{r e f}\right)^{2}}{\sum_{i=1}^{n}\left(r e f_{i}-\overline{r e f}\right)^{2}} . \\
\text { Intercept }=\frac{\sum_{i=1}^{n}\left(\text { data }_{i}-{\text { Slope } \left.\times r e f_{i}\right)}_{n} .\right.}{n} .
\end{gathered}
$$

Where, $\overline{r e f}$ is the average of the references. The agreement is better when the regression line is closer to the 1:1 line.

\section{Results}

\subsection{Environmental variables and energy fluxes}

Table 2 shows the environmental variables and the measured energy fluxes at six EC sites. It should be noted that the soil moisture in the wetland was set as $50.00 \%$. The topsoil moisture (at 2 $\mathrm{cm}$ depth) at six EC sites generally increased with increasing vegetation coverage. On the contrary, the surface temperature generally decreased with increasing vegetation coverage with the air temperature being almost similar at all six sites. In general, the relative humidity was higher at vegetated sites (e.g., 45.37\% at wetland site) than at non-vegetated sites (e.g., 39.60\% at desert site). However, the opposite was true for wind speed (e.g., $1.63 \mathrm{~m} / \mathrm{s}$ at orchard site; 3.62 $\mathrm{m} / \mathrm{s}$ at Gobi site).

With respect to the energy fluxes, $\mathrm{Rn}$ and $\mathrm{LE}$ were higher at vegetated sites than at non-vegetated sites. In contrast, Hs was considerably lower at vegetated sites $\left(20-60 \mathrm{~W} / \mathrm{m}^{2}\right)$ than at non-vegetated sites (approximately $120 \mathrm{~W} / \mathrm{m}^{2}$ ). Moreover, the energy fluxes at mixed site (village) fell in the range between those at vegetated sites and those at non-vegetated sites. As 
shown in Table 2, the energy closure residual (i.e., the difference between $\mathrm{Rn}-\mathrm{Gs}$ and $\mathrm{Hs}+\mathrm{LE}$ ) was higher at orchard and desert sites $\left(70-110 \mathrm{~W} / \mathrm{m}^{2}\right)$ than at other sites $\left(<20 \mathrm{~W} / \mathrm{m}^{2}\right)$. The energy closure ratio (i.e., (Hs+LE)/(Rn-Gs)) (i.e., another expression of energy imbalance) was close to 1.0 at wetland, maize and village sites. The ratio was however far from 1.0 at orchard, Gobi and desert sites, indicating a significant energy imbalance at those three sites.

Table 2 Statistics of environmental variables and energy fluxes at six EC sites

\begin{tabular}{|c|c|c|c|c|c|c|c|}
\hline \multirow{2}{*}{ Parameter } & \multirow{2}{*}{ Statistic variable } & \multicolumn{6}{|c|}{ Site } \\
\hline & & Wetland & Maize & Orchard & Village & Gobi & Desert \\
\hline \multirow{4}{*}{ SM (\%) } & Mean & 50.00 & 21.40 & 26.80 & 14.63 & 13.89 & 6.40 \\
\hline & $\mathrm{SD}$ & 0.00 & 6.64 & 5.97 & 4.22 & 3.96 & 1.80 \\
\hline & Max & 50.00 & 52.40 & 45.87 & 24.31 & 23.84 & 10.21 \\
\hline & Min & 50.00 & 10.34 & 17.67 & 4.16 & 6.63 & 3.02 \\
\hline \multirow{4}{*}{ Ts $(\mathrm{K})$} & Mean & 297.38 & 299.93 & 295.54 & 308.65 & 305.59 & 310.55 \\
\hline & $\mathrm{SD}$ & 4.60 & 4.99 & 3.74 & 9.51 & 8.59 & 9.63 \\
\hline & Max & 306.46 & 314.35 & 304.87 & 328.27 & 325.51 & 328.60 \\
\hline & Min & 277.63 & 280.93 & 279.74 & 282.38 & 286.76 & 286.78 \\
\hline \multirow{4}{*}{ RH (\%) } & Mean & 45.37 & 48.24 & 45.24 & 43.96 & 42.13 & 39.60 \\
\hline & $\mathrm{SD}$ & 16.72 & 15.82 & 16.69 & 17.74 & 18.50 & 17.46 \\
\hline & Max & 91.97 & 100.00 & 96.10 & 93.07 & 89.47 & 85.77 \\
\hline & Min & 11.91 & 13.72 & 11.87 & 9.10 & 8.34 & 11.22 \\
\hline \multirow{4}{*}{$\mathrm{WS}(\mathrm{m} / \mathrm{s})$} & Mean & 2.57 & 2.27 & 1.63 & 2.08 & 3.62 & 3.13 \\
\hline & $\mathrm{SD}$ & 1.57 & 1.16 & 0.75 & 0.93 & 2.04 & 1.41 \\
\hline & Max & 9.35 & 8.49 & 5.71 & 7.50 & 14.27 & 8.76 \\
\hline & Min & 0.14 & 0.41 & 0.00 & 0.62 & 0.00 & 0.30 \\
\hline \multirow{4}{*}{$\mathrm{Ta}(\mathrm{K})$} & Mean & 296.56 & 296.13 & 296.86 & 296.96 & 295.88 & 296.65 \\
\hline & SD & 4.59 & 4.42 & 4.40 & 4.50 & 4.44 & 4.61 \\
\hline & Max & 307.84 & 306.26 & 307.47 & 307.54 & 304.97 & 309.10 \\
\hline & Min & 279.00 & 278.51 & 281.36 & 282.93 & 282.82 & 280.84 \\
\hline \multirow{4}{*}{$\mathrm{LE}\left(\mathrm{W} / \mathrm{m}^{2}\right)$} & Mean & 277.89 & 356.28 & 281.27 & 132.52 & 77.27 & 73.40 \\
\hline & $\mathrm{SD}$ & 131.14 & 173.10 & 134.67 & 63.18 & 77.76 & 57.30 \\
\hline & Max & 658.43 & 1104.60 & 693.11 & 387.07 & 575.51 & 366.71 \\
\hline & Min & 7.48 & 4.43 & 18.09 & 9.11 & -45.28 & 0.07 \\
\hline \multirow{4}{*}{$\mathrm{Hs}\left(\mathrm{W} / \mathrm{m}^{2}\right)$} & Mean & 25.44 & 38.21 & 57.08 & 94.04 & 119.80 & 117.96 \\
\hline & $\mathrm{SD}$ & 48.46 & 59.78 & 59.14 & 57.42 & 81.97 & 74.50 \\
\hline & Max & 239.25 & 314.88 & 280.44 & 368.33 & 401.40 & 351.49 \\
\hline & Min & -128.70 & -71.81 & -104.69 & -35.47 & -14.47 & -6.12 \\
\hline \multirow{4}{*}{$\mathrm{Rn}\left(\mathrm{W} / \mathrm{m}^{2}\right)$} & Mean & 403.29 & 439.23 & 496.13 & 356.42 & 308.78 & 336.80 \\
\hline & $\mathrm{SD}$ & 195.99 & 189.37 & 213.31 & 162.62 & 159.88 & 164.88 \\
\hline & Max & 795.13 & 747.90 & 899.00 & 768.13 & 693.07 & 806.43 \\
\hline & Min & -14.58 & -3.94 & -6.89 & -7.90 & -50.33 & -33.12 \\
\hline \multirow{4}{*}{ Gs $\left(\mathrm{W} / \mathrm{m}^{2}\right)$} & Mean & 93.00 & 33.77 & 57.42 & 120.61 & 131.30 & 73.98 \\
\hline & $\mathrm{SD}$ & 75.98 & 57.50 & 94.87 & 111.51 & 112.92 & 56.28 \\
\hline & Max & 270.19 & 266.71 & 614.40 & 386.50 & 461.02 & 211.38 \\
\hline & Min & -72.19 & -260.68 & -191.19 & -313.74 & -216.65 & -57.68 \\
\hline \multirow{4}{*}{$\mathrm{Rn}-\mathrm{Gs}-\mathrm{LE}-\mathrm{Hs}\left(\mathrm{W} / \mathrm{m}^{2}\right)$} & Mean & 6.96 & 10.98 & 100.36 & 9.26 & -19.60 & 71.46 \\
\hline & $\mathrm{SD}$ & 65.77 & 115.60 & 115.99 & 84.20 & 70.74 & 70.79 \\
\hline & Max & 188.25 & 353.47 & 692.35 & 344.64 & 253.57 & 386.18 \\
\hline & Min & -258.02 & -494.83 & -527.57 & -224.85 & -309.42 & -152.95 \\
\hline \multirow{4}{*}{$(\mathrm{LE}+\mathrm{Hs}) /(\mathrm{Rn}-\mathrm{Gs})$} & Mean & 1.00 & 0.99 & 0.80 & 1.02 & 1.16 & 0.76 \\
\hline & $\mathrm{SD}$ & 0.33 & 0.36 & 0.57 & 0.56 & 3.45 & 1.08 \\
\hline & Max & 6.80 & 3.36 & 12.43 & 8.74 & 67.48 & 7.65 \\
\hline & Min & 0.26 & -0.07 & -2.49 & -5.10 & -40.24 & -24.72 \\
\hline
\end{tabular}

Note: SM, soil moisture; Ts, surface temperature; RH, relative humidity; WS, wind speed; Ta, air temperature; Rn, surface net radiation; Gs, surface soil heat flux; LE, latent heat flux measured by EC; Hs, sensible heat flux; Rn-Gs-LE-Hs, energy closure residual; $(\mathrm{LE}+\mathrm{Hs}) /(\mathrm{Rn}-\mathrm{Gs})$, energy closure ratio; SD, stand deviation; Max, maximum; Min, minimum. 
As shown in Figure 2a, advective enhancement was indicated by negative advections ranging from -50 to $-45 \mathrm{~W} / \mathrm{m}^{2}$ at wetland and maize sites and advective depression was suggested by positive advections ranging from 50 to $126 \mathrm{~W} / \mathrm{m}^{2}$ at other sites. The percentage contributions of advection to LE (Fig. 2b) indicated that the advection significantly affects the LE at non-vegetated sites (Gobi and desert).
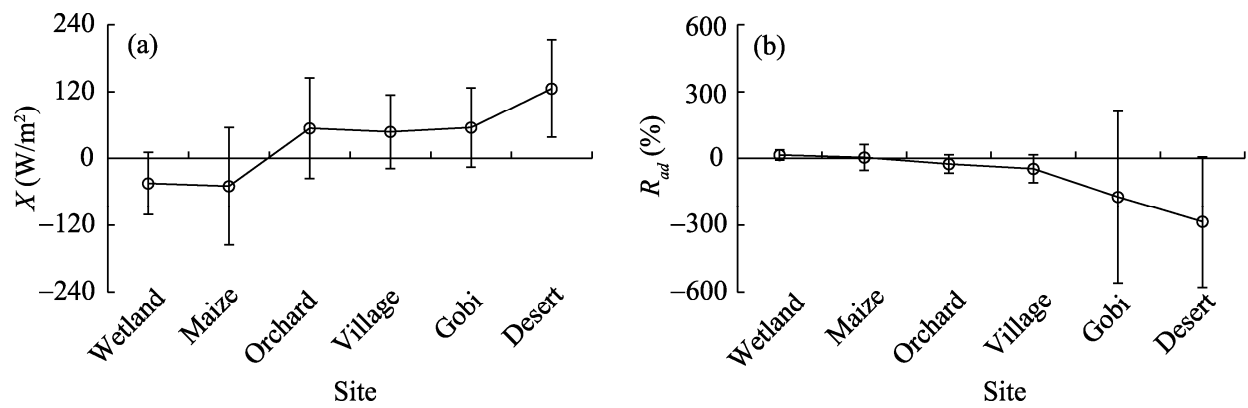

Fig. 2 (a) Mean (marked by cycles) and standard deviation (marked by bars) of the advection $(X)$ and (b) percentage contributions of advection to LE $\left(R_{a d}\right)$ at six EC sites

\subsection{Comparison of BR and ER approaches}

Figure 3 shows the comparisons between LE (i.e., latent heat flux) and BRLE (i.e., Bowen ratio-corrected LE with soil heat storage correction) and between LE and ERLE (i.e., energy balance-corrected LE with soil heat storage correction) at six EC sites. Our comparisons demonstrated that both the BR and ER approaches were able to correct the negative biases in LE measurements. The site-to-site comparison revealed that except at village site (see Fig. 3-a4), BRLE were well comparable to LE at all of other five sites (especially at wetland, maize and orchard sites) and the good comparability was expressed by higher $R^{2}$ values and lower Slope values. It should be pointed out that the corrected LE values were significantly higher than the EC-measured LE values, further confirming the underestimation problems of EC-based LE measurements. For example, the BR-corrected LE was about $10 \mathrm{~W} / \mathrm{m}^{2}$ higher than the EC-measured LE at wetland, maize and village sites and was up $85 \mathrm{~W} / \mathrm{m}^{2}$ higher at orchard site (see Fig. 3-a1-a4). The ER-corrected LE was also about $10 \mathrm{~W} / \mathrm{m}^{2}$ at wetland, maize and village sites and was up to $100 \mathrm{~W} / \mathrm{m}^{2}$ at orchard site (see Fig. 3-b1-b4). The exception occurred at Gobi site where BR-corrected LE was about $4 \mathrm{~W} / \mathrm{m}^{2}$ lower than the EC-measured LE (see Fig. 3-a5) and where ER-corrected LE was about $20 \mathrm{~W} / \mathrm{m}^{2}$ lower than the EC-measured LE (see Fig. 3-b5).

The bottom two panels of Figure 3 (i.e., c1-c6) show the comparisons between BRLE and ERLE at all six EC sites. BRLE was in good agreement with ERLE at vegetated and mixed sites $\left(R^{2}>0.90\right)$. In contrast, relatively large discrepancies existed between ERLE and BRLE at two non-vegetated sites $\left(R^{2}<0.90\right)$. As shown in Table 3, the difference was smallest at wetland site $\left(\right.$ Bias $=1.73 \mathrm{~W} / \mathrm{m}^{2} ; \mathrm{RMSE}=12.06 \mathrm{~W} / \mathrm{m}^{2}$ ) and largest at desert site (Bias $=-44.41 \mathrm{~W} / \mathrm{m}^{2}$; $\mathrm{RMSE}=66.90 \mathrm{~W} / \mathrm{m}^{2}$ ). Overall, the BR and ER approaches yielded similar results at vegetated and mixed sites, and larger discrepancies occurred at non-vegetated sites.

\subsection{Influences of meteorological factors on BR and ER approaches}

In this study, wind speed, relative humidity, and temperature difference between land surface and air were chosen to analyze the influences of meteorological factors on BR and ER approaches. The reasons are as follows: (1) they are the most important meteorological factors; (2) the wind speed may affect the advection flux; (3) the humidity may affect the signal frequency for gas analyzer; and (4) the temperature difference between land surface and air may affect the air dynamics below the measurement height. As shown in Figure 2b, the percentage contributions of advection to LE indicated that the advection significantly affects the LE at non-vegetated sites (Gobi and desert), we thus compared BRLE and ERLE at different levels of wind speed, air humidity and surface-air temperature difference at non-vegetated sites (Table 4; Fig. 4). 

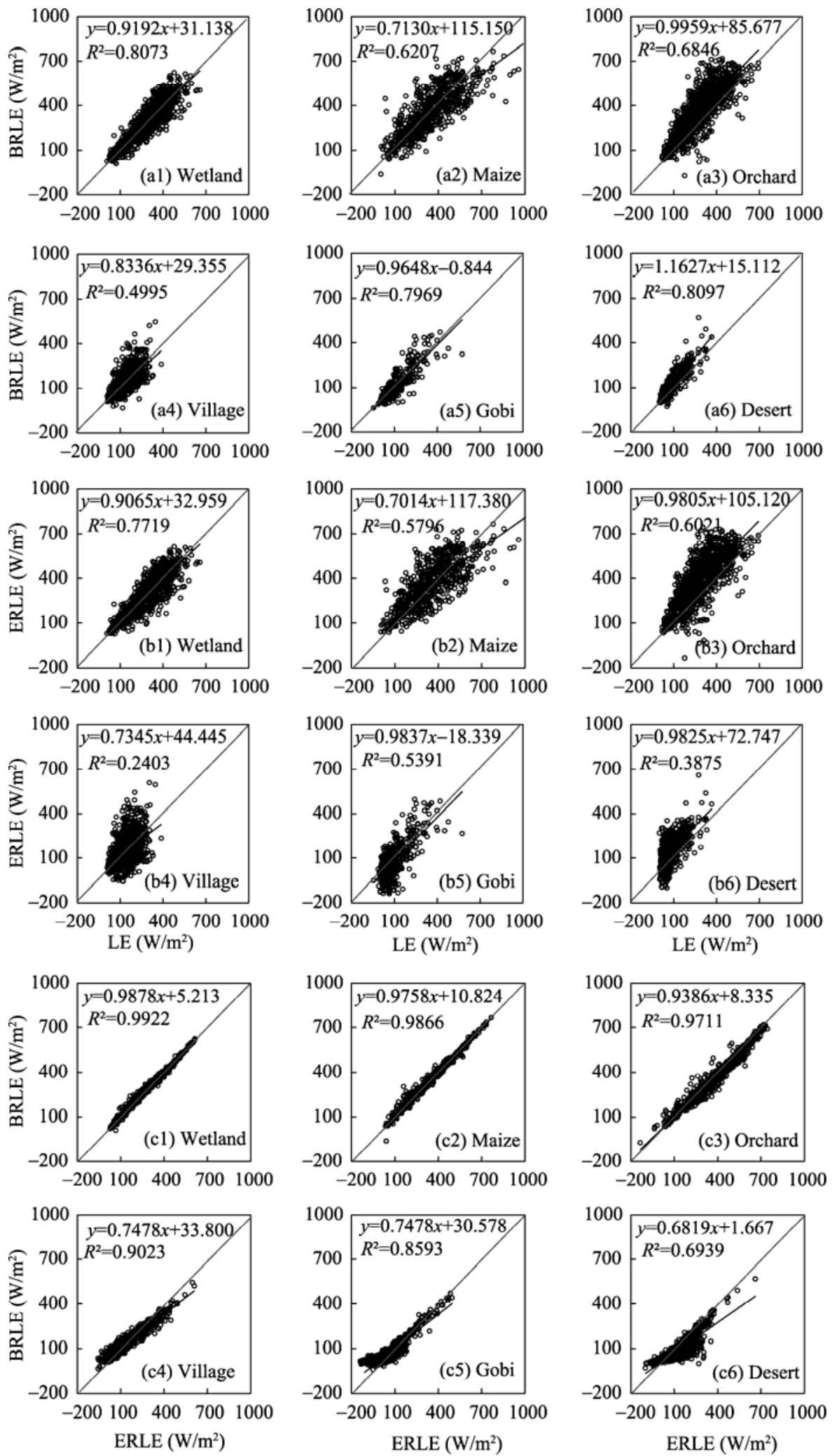

Fig. 3 Comparisons between LE and BRLE (a1-a6), LE and ERLE (b1-b6), and ERLE and BRLE (c1-c6) at six EC sites. LE, latent heat flux measured by EC; BRLE, Bowen ratio-corrected LE with soil heat storage correction; ERLE, energy balance residual-corrected LE with soil heat storage correction. 
PAN Xin et al.: Two energy balance closure approaches: applications and comparisons over an...

Table 3 Statistics of comparisons between LE and BRLE, LE and ERLE, and BRLE and ERLE at six EC sites

\begin{tabular}{ccrrrrrr}
\hline \multirow{2}{*}{ Item } & \multirow{2}{*}{$\begin{array}{c}\text { Statistic variable } \\
\left(\mathrm{W} / \mathrm{m}^{2}\right)\end{array}$} & Wetland & Maize & Orchard & Village & Gobi & Desert \\
\cline { 3 - 8 } & Bias & 8.70 & 12.92 & 84.51 & 7.31 & -3.57 & 27.05 \\
LE vs BRLE & SD & 59.84 & 108.52 & 90.83 & 53.76 & 37.97 & 33.62 \\
& RMSE & 60.44 & 109.20 & 124.03 & 54.24 & 38.11 & 43.14 \\
& Bias & 6.96 & 10.98 & 99.63 & 9.26 & -19.60 & 71.46 \\
LE vs ERLE & SD & 65.77 & 115.60 & 107.13 & 84.20 & 70.74 & 70.79 \\
& RMSE & 66.10 & 116.03 & 146.26 & 84.67 & 73.36 & 100.56 \\
& Bias & 1.73 & 1.94 & -15.11 & -1.95 & 16.03 & -44.41 \\
BRLE vs ERLE & SD & 11.94 & 18.53 & 29.42 & 33.35 & 41.03 & 50.06 \\
& RMSE & 12.06 & 18.62 & 33.06 & 33.40 & 44.03 & 66.90 \\
\hline
\end{tabular}

Note: BRLE, Bowen ratio-corrected LE with soil heat storage correction; ERLE, energy balance residual-corrected LE with soil heat storage correction; SD, stand deviation; RMSE, root mean square error.

Table 4 Statistics of comparisons between BRLE and ERLE at non-vegetated sites at different levels of relative humidity (RH), wind speed (WS) and surface-air temperature difference (Ts-Ta)

\begin{tabular}{|c|c|c|c|c|c|c|c|}
\hline \multirow{3}{*}{ Parameter } & \multirow{3}{*}{ Classification } & \multicolumn{3}{|c|}{ Gobi site } & \multicolumn{3}{|c|}{ Desert site } \\
\hline & & Bias & SD & RMSE & Bias & SD & RMSE \\
\hline & & \multicolumn{3}{|c|}{$\left(\mathrm{W} / \mathrm{m}^{2}\right)$} & \multicolumn{3}{|c|}{$\left(\mathrm{W} / \mathrm{m}^{2}\right)$} \\
\hline \multirow{3}{*}{ WS (m/s) } & $<2$ & 10.90 & 32.40 & 34.06 & -44.31 & 38.23 & 58.46 \\
\hline & $2-4$ & 21.59 & 41.67 & 46.87 & -41.36 & 44.96 & 61.06 \\
\hline & $>4$ & 10.38 & 43.06 & 44.21 & -50.80 & 66.12 & 83.26 \\
\hline \multirow{3}{*}{ RH (\%) } & $<30$ & 25.57 & 46.34 & 52.83 & -46.74 & 55.30 & 72.34 \\
\hline & $30-60$ & 17.52 & 41.01 & 44.54 & -48.65 & 50.54 & 70.11 \\
\hline & $>60$ & -2.36 & 22.46 & 22.51 & -24.55 & 23.33 & 33.80 \\
\hline \multirow{3}{*}{ Ts-Ta (K) } & $-5-5$ & 1.02 & 38.60 & 38.53 & -9.14 & 17.88 & 20.00 \\
\hline & $5-15$ & 18.06 & 38.08 & 42.08 & -30.48 & 43.21 & 52.83 \\
\hline & $15-25$ & 31.66 & 41.40 & 52.04 & -65.77 & 51.88 & 83.73 \\
\hline
\end{tabular}

Wind speed was divided into $<2,2-4$ and $>4 \mathrm{~m} / \mathrm{s}$, representing gentle, moderate and strong winds, respectively. Generally speaking, the discrepancy between BRLE and ERLE increased with increasing wind speeds. That is, both the $R^{2}$ values and the Slope values were lower at high wind speed $(>4 \mathrm{~m} / \mathrm{s})$ than those at low wind speed $(<2 \mathrm{~m} / \mathrm{s})$. The Bias, SD and RMSE, however, refused to show any patterns (see Fig. 4-a1-a6).

Relative humidity was divided into $<30 \%, 30 \%-60 \%$ and $>60 \%$, corresponding to dry, moderate and moist air conditions, respectively. As demonstrated by both the $R^{2}$ values and the Slope values, the higher the air moisture, the better the agreement between BRLE and ERLE was (see Fig. 4-b1-b6). The lowest Bias, SD and RMSE values at highest level of air humidity also suggested that the difference between BRLE and ERLE was smallest under the highest moisture condition (Table 4).

The surface-air temperature difference was divided into $-5-5,5-15$ and $15-25 \mathrm{~K}$, corresponding to slight, moderate and large temperature differences, respectively. In general, the discrepancy between BRLE and ERLE was larger at larger surface-air temperature difference (Fig. 4-c1-c6). That is, both the $R^{2}$ values and the Slope values were higher at lower surface-air temperature difference $(-5-5 \mathrm{~K})$ than those at larger surface-air temperature difference $(15-25 \mathrm{~K})$. The highest Bias, SD and RMSE values also indicated that the agreement between BRLE and ERLE was poorest at the largest surface-air temperature difference (Table 4). 

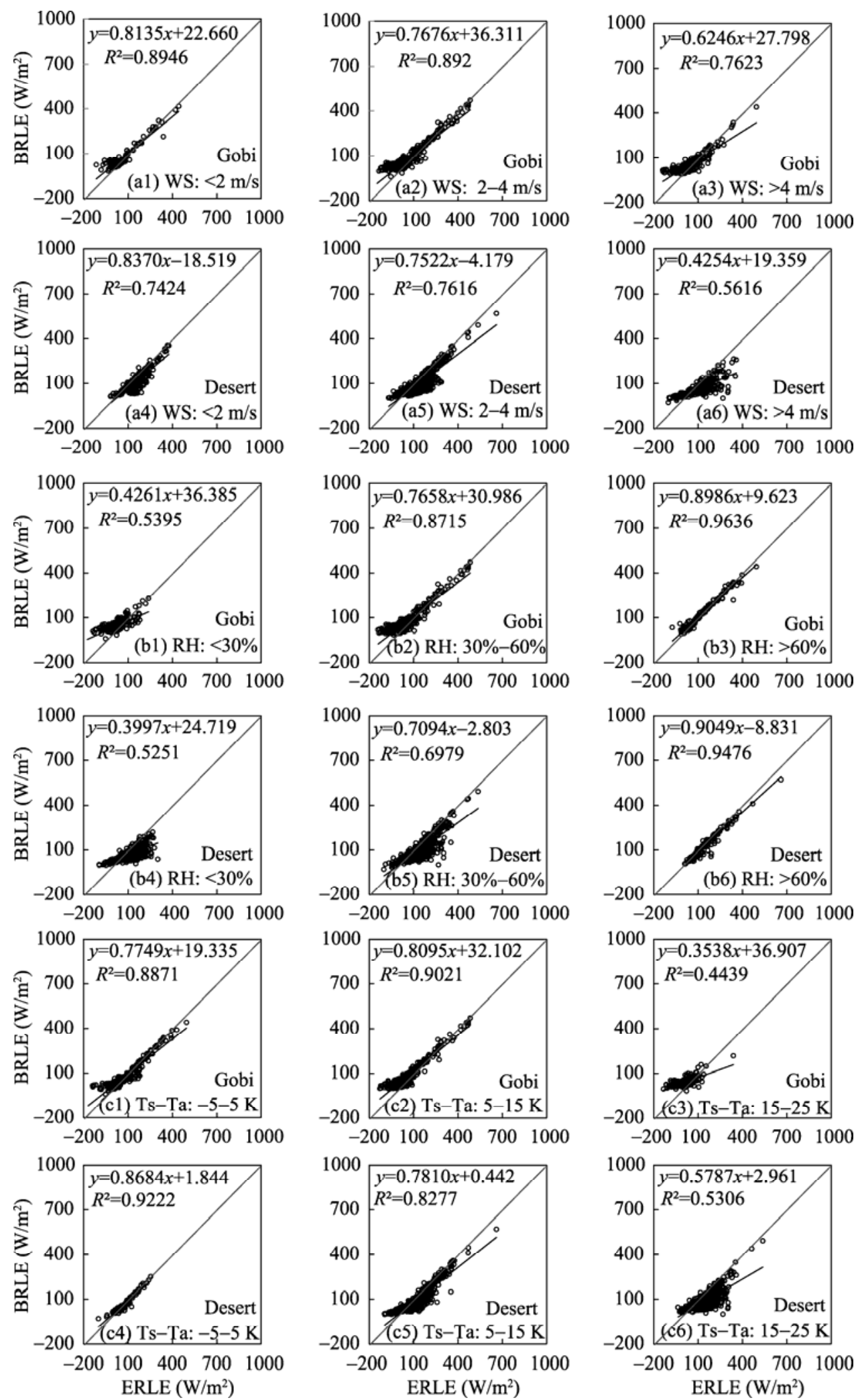

Fig. 4 Comparisons between BRLE and ERLE at different levels of WS (a1-a6), RH (b1-b6) and Ts-Ta (c1-c6) at non-vegetated sites (Gobi and desert sites). WS, wind speed; RH, relative humidity; Ts-Ta, surface-air temperature difference. 


\section{Discussion}

As mentioned before, the energy balance closure (i.e., energy imbalance) has been one of the major challenges in the studies of energy exchange processes within the land-atmosphere interface. There are many possible causes for energy balance closure and these causes are directly or indirectly related to following factors: canopy layer, spatial scale, soil heat storage, horizontal advection, heat storage in the developing boundary layer below the measurement height, frequency response of the sensors, measuring errors of turbulent fluxes, etc. (Foken, 2008). However, only a small number of these factors dictate the energy balance closure in a specific region. For example, the energy stored in the canopy layer has a non-negligible influence on energy balance in a forested region (Lindroth et al., 2010). Another example is the spatial scale problem (discrepancies of footprint among instruments) that may exert a significant influence on energy balance in a region with inhomogeneous land surfaces. In a region with poor vegetation and high wind speed, the horizontal advection may affect the energy balance (Foken, 2008). In our study, the percentage contributions of advection to LE were rather high (ranging from $-286 \%$ to $-176 \%$ ) at non-vegetated sites (Gobi and desert) with high wind speed ( $>4 \mathrm{~m} / \mathrm{s}$ ).

Many approaches were proposed to correct the energy balance closure and BR and ER approaches were most frequently adopted (Twine et al., 2000; Amiro, 2009; Allen et al., 2011). In terms of the physics underlying the BR approach, EC-based measurements underestimate turbulent fluxes and the underestimations of LE and $\mathrm{Hs}$ are in accordance with the Bowen ratios. Therefore, this approach actually corrects the energy imbalance by distributing the residual energy according to the Bowen ratios. Mathematically speaking, the BR approach assumes that LE and Hs have similar levels of accuracies (Twine et al., 2000). However, based on in situ observations, EC is more accurate for estimating Hs than for estimating LE (Kristensen et al., 1997; Mauder et al., 2006, 2007; Xu et al., 2013). Furthermore, small seasonal differences in the random error of Hs and large seasonal differences in the random error of LE were documented (Richardson et al., 2006). Thus, cautions should be exercised when applying the BR approach to the circumstances where the accuracy levels of $\mathrm{Hs}$ and LE measurements differ significantly (Kidston et al., 2010). ER approach is based on energy balance principle ( $\mathrm{Rn}-\mathrm{Gs}=\mathrm{LE}+\mathrm{Hs}$ ), assuming that the available energy flux (Rn-Gs) is equal to the sum of measured latent and sensible heat fluxes (LE+Hs). Obviously, this approach relies only on the measurements of Rn, Gs and Hs (Allen et al., 2011). Therefore, the ER approach may provide more accurate LE data compared to the BR approach if the accuracies of Rn, Gs and Hs measurements can be insured (Burba and Anderson, 2010; Allen et al., 2011; Liu et al., 2012; Hu et al., 2015). However, ER approach may not work well when energy storage value is larger than other flux values (Meyers and Hollinger, 2004; Amiro, 2009).

In this study, BRLE was in good agreement with ERLE at vegetated and mixed sites. But, a relatively large discrepancy existed between ERLE and BRLE at two non-vegetated sites and the discrepancy was even larger under strong winds at desert area. This is likely due to the advective flux divergence (Foken, 2008). Therefore, the acceptancy of BR approach is different from that of ER approach at desert area, especially under strong winds. The difference between BRLE and ERLE was smallest under moist air conditions likely due to more accurate LE values under high air humidity conditions (Moncrieff et al., 1997). The agreement between BRLE and ERLE was poorer at larger land-air temperature differences and this may be attributable to the unknown air dynamics below the measurement height (Leuning et al., 2012). The difference between BRLE and ERLE is likely related to the degree of energy balance closure. The energy closure ratio was approximately close to 1.0 at wetland, maize and village sites but was far from 1.0 at orchard, Gobi and desert sites, indicating a significant energy imbalance at those three latter sites. Generally, ER approach and BR approach yielded similar results over the oasis area but generated dissimilar results over the desert area. According to our study, ER approach seems to be more reasonable for LE correction in desert area compared to BR approach. In addition, the ER approach seems to be a better alternative than the BR approach if EC-based LE measurements are severely underestimated. All in all, selection of approaches is actually dependent on the circumstances (Verstraeten et al., 2008; Li et al., 2009). 


\section{Conclusions}

EC system has become a primary method for measuring LE, but it usually underestimates the LE, resulting in energy balance closure. To obtain more accurate LE in the studies of energy balance, we applied BR and ER approaches to correct the original EC-based LE measurements at six EC sites of the HiWATER. Our study showed that the mean energy closure ratio was close to 1.0 at wetland, maize and village sites but far from 1.0 at orchard, Gobi and desert sites, indicating a significant energy imbalance at those three latter sites. ER approach and BR approach yielded similar results over the oasis area but generated dissimilar results over the desert area. And, the difference was especially large over desert area when air humidity was low, wind was strong, and surface-air temperature difference was large. ER approach may be more reliable than BR approach for LE correction in desert region. To sum up, cautions should be exercised when selecting LE-correcting approaches.

\section{Acknowledgements}

This study was supported by the National Natural Science Foundation of China $(41430855,91125004)$. We thank the Cold and Arid Regions Science Data Center at Lanzhou for providing observation data (http://westdc.westgis.ac.cn). We also thank to Prof. LIU Shaomin and Dr. XU Ziwei for their kind assistances in field observation.

\section{References}

Allen R G, Pereira L S, Howell T A, et al. 2011. Evapotranspiration information reporting: I. Factors governing measurement accuracy. Agricultural Water Management, 98(6): 899-920.

Amiro B. 2009. Measuring boreal forest evapotranspiration using the energy balance residual. Journal of Hydrology, 366(1-4): $112-118$.

Aubinet M, Grelle A, Ibrom A, et al. 1999. Estimates of the annual net carbon and water exchange of forests: The EUROFLUX methodology. Advances in Ecological Research, 30: 113-175.

Aubinet M, Vesala T, Papale D. 2012. Eddy Covariance: A Practical Guide to Measurement and Data Analysis. Netherlands: Springer, 40-171.

Baldocchi D, Falge E, Gu L H, et al. 2001. FLUXNET: A new tool to study the temporal and spatial variability of ecosystem-scale carbon dioxide, water vapor, and energy flux densities. Bulletin of the American Meteorological Society, 82(11): 2415-2434.

Barr A G, van der Kamp G, Black T A, et al. 2012. Energy balance closure at the BERMS flux towers in relation to the water balance of the White Gull Creek watershed 1999-2009. Agricultural and Forest Meteorology, 153: 3-13.

Blundell J E, Stubbs R J, Hughes D A, et al. 2003. Cross talk between physical activity and appetite control: does physical activity stimulate appetite? Proceedings of the Nutrition Society, 62: 651-661.

Bowen I S. 1926. The ratio of heat losses by conduction and by evaporation from any water surface. Physical Review, 27(6): 779-787.

Bray G, Bouchard C, Hill J O, et al. 2003. Energy expenditure and physical activity. In: Bray G, Bouchard C. Handbook of Obesity ( $2^{\text {nd }}$ ed.). New York: Marcel Dekker, Inc., 631-654.

Burba G, Anderson D. 2010. Brief Practical Guide to Eddy Covariance Flux Measurements: Principles and Workflow Examples for Scientific and Industrial Applications. Lincoln, Nebraska: LI-COR Biosciences, 11-28.

Castellví F, Snyder R L, Baldocchi D D. 2008. Surface energy-balance closure over rangeland grass using the eddy covariance method and surface renewal analysis. Agricultural and Forest Meteorology, 148(6-7): 1147-1160.

Foken T. 2008. The energy balance closure problem: An overview. Ecological Applications, 18(6): 1351-1367.

Franssen H J H, Stöckli R, Lehner I, et al. 2010. Energy balance closure of eddy-covariance data: A multisite analysis for European FLUXNET stations. Agricultural and Forest Meteorology, 150(12): 1553-1567.

Haverd V, Cuntz M, Leuning R, et al. 2007. Air and biomass heat storage fluxes in a forest canopy: Calculation within a soil vegetation atmosphere transfer model. Agricultural and Forest Meteorology, 147(3-4): 125-139.

Heusinkveld B G, Jacobs A F G, Holtslag A A M, et al. 2004. Surface energy balance closure in an arid region: Role of soil heat flux. Agricultural and Forest Meteorology, 122(1-2): 21-37.

Hu M G, Wang J H, Ge Y, et al. 2015. Scaling flux tower observations of sensible heat flux using weighted area-to-area 
regression Kriging. Atmosphere, 6(8): 1032-1044.

Kidston J, Brümmer C, Black T A, et al. 2010. Energy balance closure using eddy covariance above two different land surfaces and implications for $\mathrm{CO}_{2}$ flux measurements. Boundary-Layer Meteorology, 136(2): 193-218.

Kristensen L, Mann J, Oncley S P, et al. 1997. How close is close enough when measuring scalar fluxes with displaced sensors? Journal of Atmospheric and Oceanic Technology, 14(4): 814-821.

Lee X, Massman W, Law B. 2004. Handbook of Micrometeorology: A Guide for Surface Flux Measurement and Analysis. Dordrecht: Kluwer Academic Publishers, 181-203.

Leuning R, van Gorsel E, Massman W J, et al. 2012. Reflections on the surface energy imbalance problem. Agricultural and Forest Meteorology, 156: 65-74.

Li X, Cheng G D, Liu S M, et al. 2013. Heihe watershed allied telemetry experimental research (HiWATER): Scientific objectives and experimental design. Bulletin of the American Meteorological Society, 94(8): 1145-1160.

Li Z L, Tang R L, Wan Z M, et al. 2009. A review of current methodologies for regional evapotranspiration estimation from remotely sensed data. Sensors, 9(5): 3801-3853.

Lindroth A, Mölder M, Lagergren F. 2010. Heat storage in forest biomass improves energy balance closure. Biogeosciences, 7(1): 301-313.

Liu S M, Xu Z W, Wang W Z, et al. 2011. A comparison of eddy-covariance and large aperture scintillometer measurements with respect to the energy balance closure problem. Hydrology and Earth System Sciences, 15(4): 1291-1306.

Liu S M, Xu Z W, Wang W Z. 2012. The use of large aperture scintillometer and eddy covariance system for monitoring energy and water vapour fluxes over different surfaces in the Heihe River Basin, China. In: Proceedings of a Symposium Held at Jackson Hole. Wyoming, USA: IAHS-AISH Publication, 184-190.

Liu Y B, Hiyama T, Yasunari T, et al. 2012. A nonparametric approach to estimating terrestrial evaporation: Validation in eddy covariance sites. Agricultural and Forest Meteorology, 157: 49-59.

Mauder M, Liebethal C, Göckede M, et al. 2006. Processing and quality control of flux data during LITFASS-2003. Boundary-Layer Meteorology, 121(1): 67-88.

Mauder M, Oncley S P, Vogt R, et al. 2007. The energy balance experiment EBEX-2000. Part II: Intercomparison of eddy-covariance sensors and post-field data processing methods. Boundary-Layer Meteorology, 123(1): $29-54$.

McNaughton K G. 1983. The direct effect of shelter on evaporation rates: Theory and an experimental test. Agricultural Meteorology, 29(2): 125-136.

Mercado L M, Bellouin N, Sitch S, et al. 2009. Impact of changes in diffuse radiation on the global land carbon sink. Nature, 458(7241): 1014-1018.

Meyers T P, Hollinger S E. 2004. An assessment of storage terms in the surface energy balance of maize and soybean. Agricultural and Forest Meteorology, 125(1-2): 105-115.

Moiwo J P, Tao F L. 2015. Contributions of precipitation, irrigation and soil water to evapotranspiration in (semi)-arid regions. International Journal of Climatology, 35(6): 1079-1089.

Moncrieff J B, Massheder J M, de Bruin H, et al. 1997. A system to measure surface fluxes of momentum, sensible heat, water vapour and carbon dioxide. Journal of Hydrology, 188-189: 589-611.

Nagol J R, Vermote E F, Prince S D. 2009. Effects of atmospheric variation on AVHRR NDVI data. Remote Sensing of Environment, 113(2): 392-397.

Oliphant A J, Grimmond C S B, Zutter H N, et al. 2004. Heat storage and energy balance fluxes for a temperate deciduous forest. Agricultural and Forest Meteorology, 126(3-4): 185-201.

Oncley S P, Foken T, Vogt R, et al. 2007. The energy balance experiment EBEX-2000. Part I: Overview and energy balance. Boundary-Layer Meteorology, 123(1): 1-28.

Richardson A D, Hollinger D Y, Burba G G, et al. 2006. A multi-site analysis of random error in tower-based measurements of carbon and energy fluxes. Agricultural and Forest Meteorology, 136(1-2): 1-18.

Schotanus P, Nieuwstadt F T M, De Bruin H A R. 1983. Temperature measurement with a sonic anemometer and its application to heat and moisture fluxes. Boundary-Layer Meteorology, 26(1): 81-93.

Smith D M, Jarvis P G, Odongo J CW. 1997. Energy budgets of windbreak canopies in the Sahel. Agricultural and Forest Meteorology, 86(1-2): 33-49.

Squires G L. 2001. Practical Physics. Cambridge: Cambridge University Press, 1-41.

Stoy P C, Mauder M, Foken T. 2013. A data-driven analysis of energy balance closure across FLUXNET research sites: The role of landscape scale heterogeneity. Agricultural and Forest Meteorology, 171-172: 137-152.

Twine T E, Kustas W P, Norman J M, et al. 2000. Correcting eddy-covariance flux underestimates over a grassland. Agricultural and Forest Meteorology, 103(3): 279-300. 
Verstraeten W W, Veroustraete F, Feyen J. 2008. Assessment of evapotranspiration and soil moisture content across different scales of observation. Sensors, 8(1): 70-117.

Wang J M, Wang W Z, Liu S M, et al. 2009. The problems of surface energy balance closure-an overview and case study. Advances in Earth Science, 24(7): 705-713. (in Chinese)

Wang J M, Zhuang J X, Wang W Z, et al. 2015. Assessment of uncertainties in eddy covariance flux measurement based on intensive flux matrix of HiWATER-MUSOEXE. IEEE Geoscience and Remote Sensing Letters, 12(2): 259-263.

Wang K C, Dickinson R E. 2012. A review of global terrestrial evapotranspiration: Observation, modeling, climatology, and climatic variability. Reviews of Geophysics, 50(2): RG2005, doi: 10.1029/2011RG000373.

Webb E K, Pearman G I, Leuning R. 1980. Correction of flux measurements for density effects due to heat and water vapour transfer. Quarterly Journal of the Royal Meteorological Society, 106(447): 85-100.

Wilczak J M, Oncley S P, Stage S A. 2001. Sonic anemometer tilt correction algorithms. Boundary-Layer Meteorology, 99(1): $127-150$.

Wild M. 2008. Short-wave and long-wave surface radiation budgets in GCMs: a review based on the IPCC-AR4/CMIP3 models. Tellus A, 60(5): 932-945.

Wilson K, Goldstein A, Falge E, et al. 2002. Energy balance closure at FLUXNET sites. Agricultural and Forest Meteorology, 113(1-4): 223-243.

Wohlfahrt G, Haslwanter A, Hörtnagl L, et al. 2009. On the consequences of the energy imbalance for calculating surface conductance to water vapour. Agricultural and Forest Meteorology, 149(9): 1556-1559.

Xu Z W, Liu S M, Li X, et al. 2013. Intercomparison of surface energy flux measurement systems used during the HiWATER-MUSOEXE. Journal of Geophysical Research, 118(23): 13140-13157.

Yang K, Wang J M. 2008. A temperature prediction-correction method for estimating surface soil heat flux from soil temperature and moisture data. Science in China series D: Earth sciences, 51(5): 721-729.

Zeweldi D A, Gebremichael M, Wang J M, et al. 2010. Intercomparison of sensible heat flux from large aperture scintillometer and eddy covariance methods: Field experiment over a homogeneous semi-arid region. Boundary-Layer Meteorology, 135(1): 151-159. 